\title{
Echocardiographic evaluation of the results of minimally invasive repair of asymptomatic mitral regurgitation
}

\author{
Witold Gerber ${ }^{1,2}$, Krzysztof Sanetra ${ }^{1,2}$, Agnieszka Drzewiecka-Gerber ${ }^{1,2}$, Justyna Jankowska-Sanetra ${ }^{3}$, \\ Andrzej Bochenek ${ }^{1,2}$, Marian Zembala ${ }^{4,5}$, Marek Cisowski ${ }^{1,2,4,5}$ \\ ${ }^{1} 1^{\text {st }}$ Department of Cardiac Surgery, American Heart of Poland, Bielsko-Biala, Poland \\ ${ }^{2}$ Centre for Cardiovascular Research and Development, American Heart of Poland, Bielsko-Biala, Poland \\ ${ }^{3} 2^{\text {nd }}$ Department of Cardiology, American Heart of Poland, Bielsko-Biala, Poland \\ ${ }^{4}$ Department of Cardiac, Vascular, and Endovascular Surgery and Transplantology, Zabrze, Poland \\ ${ }^{5}$ Medical University of Silesia, Katowice, Poland
}

\section{INTRODUCTION}

The concept of and indications for mitral valve surgery have constantly evolved. The European Association of Cardiology/European Association for Cardiothoracic Surgery (ESC/EACTS) guidelines underline that mitral valve repair (MVR) should be the preferred technique if it is expected to be durable (class of recommendation IC) [1, 2]. Many asymptomatic patients with a new diagnosis of severe mitral regurgitation (MR) do not fit the criteria for intervention. The question whether to opt for an invasive procedure in those cases remains a matter of debate. However, the five-year combined incidence of atrial fibrillation, heart failure, or cardiovascular death in nonsurgical, asymptomatic patients with normal ventricular function and severe MR was estimated at $42 \% \pm 8 \%$ [3]. Moreover, it was noted that heart failure at 10 years was less frequent after early surgery for severe MR (7\%) than after the initial medical management (23\%), and that the survival was estimated at $86 \%$ after early surgery for severe mitral valve regurgitation vs. $69 \%$ for the initial medical management at 10-year follow-up [4].

These clinical data combined with the possibility to perform an isolated MVR through right mini-thoracotomy, which allowed a satisfactory effect with minimal trauma, were the background for creating a prospective registry. The registry was started in 2012, and the 2012 ESC/EACTS criteria for mitral valve surgery were used as a reference for patient qualification. The aim of the present report is to evaluate the six-month outcomes of minimally invasive MVR and investigate the aspect of reverse remodelling in asymptomatic patients.

\section{METHODS}

All the procedures were approved by the local Bioethics Committee. The report contains data from a prospective registry that records all clinical and echocardiographic parameters from minimally invasive mitral procedures performed at our institution. For the purpose of the study, all the patients who were referred for MVR (severe MR on the basis of the ESC/EACTS criteria) and reported no symptoms preoperatively were selected for the analysis.

All the repair procedures (implantation of artificial chordae, $\mathrm{P} 2$ resection, cleft closures, etc.) were performed by the same surgeon (W.G.). Each patient received an annuloplasty ring. Intraoperative transoesophageal echocardiography was used to evaluate proper valvular function. If reintervention was needed, it was performed within the same extracorporeal circulation. Patients who finally required mitral valve replacement were reported but excluded from echocardiographic analysis in this study.

The pharmacotherapy was chosen adequately to each patient's clinical status and comorbidities. Additionally, each patient received a vitamin $\mathrm{K}$ antagonist (acenocoumarol or warfarin) with dosage adjusted to the current international normalised ratio (INR). The target INR values were 2.5-3.5. Low-molecular-weight heparin was administered until the INR was $>2$. If the patient had no other indications for anticoagulation, the vitamin $\mathrm{K}$ antagonist therapy was ceased three months after the procedure.

Every patient underwent clinical and echocardiographic assessment (transthoracic echocardiography) six months after 
Table 1. Six-month echocardiographic evaluation $(n=111)$

\begin{tabular}{lccc|} 
Parameter & Preoperatively & At six-month evaluation & $\mathbf{p}$ \\
\hline LVEF $[\%]$ & $68.0(60.5-73.0)$ & $60.0(55.0-66.0)$ & $<0.001$ \\
LVEDV $\left[\mathrm{cm}^{3}\right]$ & $165.0(128.5-202.5)$ & $106.0(90.5-124.5)$ & $<0.001$ \\
LVESV $\left[\mathrm{cm}^{3}\right]$ & $54.0(39.0-73.0)$ & $44.0(33.0-54.5)$ & $<0.001$ \\
LVESD $[\mathrm{mm}]$ & $35(30.5-39.0)$ & $32.0(28.0-35.0)$ & 0.002 \\
LVEDD $[\mathrm{mm}]$ & $58.0(53.0-64.0)$ & $50.0(46.0-54.0)$ & $<0.001$ \\
LA $_{\text {OLLUME }}\left[\mathrm{cm}^{3}\right]$ & $99.0(77.0-123.0)$ & $55.0(49.0-69.0)$ & $<0.001$ \\
LA $_{\text {AREA }}\left[\mathrm{cm}^{2}\right]$ & $26.0(23.0-30.5)$ & $18.5(16.0-21.0)$ & $<0.001$ \\
\hline
\end{tabular}

Data are shown as median (interquartile range). LVEDD — left ventricular end-diastolic diameter; LVEDV — left ventricular end-diastolic volume; LVEF — left ventricular ejection fraction; LVESD — left ventricular end-systolic diameter; LVESV — left ventricular end-systolic volume; LA ${ }_{\text {AREA }}$ — left atrial area; $\mathrm{LA}_{\text {volume }}$ - left atrial volume

the surgical procedure - the echocardiographic parameters (left ventricular end-diastolic diameter [LVEDD], left ventricular end-diastolic volume [LVEDV], left ventricular ejection fraction [LVEF], left ventricular end-systolic diameter [LVESD], left ventricular end-systolic volume [LVESV], left atrial area $\left[\mathrm{LA}_{\mathrm{AREA}}\right]$, and left atrial volume $\left.\left[\mathrm{LA}_{\mathrm{VOLUME}}\right]\right)$ were recorded in the database.

All the echocardiographic examinations (before the operation and at six-month follow-up) were performed using a GE Vivid 7 device (GE Healthcare, Chicago, IL, USA) by the same echocardiographer. Preoperative analysis included transthoracic echocardiography and transoesophageal echocardiography when necessary. Transthoracic echocardiography was performed at six-month evaluation.

\section{Statistical analysis}

The hypothesis of normal data distribution was rejected in the Shapiro-Wilk test. Consequently, a two-tailed Mann-Whitney $U$ test was used for the data analysis. The data are presented as median and interquartile range or number (percentage). The analysis was performed with MedCalc v.18.5 (MedCalc Software, Ostend, Belgium). A p-value less than 0.05 was considered statistically significant.

\section{RESULTS AND DISCUSSION}

By the time of the data analysis, there were 173 patients included in the registry (first patient was recorded in January 2012 and the last one was recorded in November 2017). A group of 114 asymptomatic patients (78 men and 36 women) referred for MVR were selected from the database. Three of them (2.6\% - two men and one woman) finally required mitral valve replacement (each received a mechanical valve) due to an unsuccessful repair and were excluded from further analysis in this report. However, those three patients remained in the database and they presented no symptoms at six-month follow-up.

An echocardiographic follow-up of 111 patients (76 men and 35 women) at the age of $49.37 \pm 14.35$ years, who underwent a successful MVR procedure, was performed. No patient was lost to follow-up. By the time of their clinical and echocardiographic evaluation, all but three (2.7\%) patients remained asymptomatic/in New York Heart Association (NYHA) class I. Two of them were in NYHA class II and III, respectively, without deterioration in echocardiographic parameters, which resulted in modification of the pharmacotherapy. One (0.9\%) patient required reoperation due to severe mitral valve dysfunction related to endocarditis. None of the patients died.

The comparison of the initial and the six-month echocardiographic evaluations showed significant differences in LVEF (median 68\% vs. 60\%; p < 0.001), LVEDV (median $165 \mathrm{~cm}^{3}$ vs. $106 \mathrm{~cm}^{3} ; \mathrm{p}<0.001$ ), LVESV (median $54 \mathrm{~cm}^{3}$ vs. $44 \mathrm{~cm}^{3} ; \mathrm{p}<0.001$ ), LVESD (median $35 \mathrm{~mm}$ vs. $32 \mathrm{~mm} ; \mathrm{p}=0.02$ ), LVEDD (median $58 \mathrm{~mm}$ vs. $50 \mathrm{~mm}$; $\mathrm{p}<0.001)$, $\mathrm{LA}_{\text {VOLUME }}$ (median $99 \mathrm{~cm}^{3}$ vs. $55 \mathrm{~cm}^{3} ; \mathrm{p}<0.001$ ), and $\mathrm{LA}_{\text {AREA }}$ (median $26 \mathrm{~cm}^{2}$ vs. $18.5 \mathrm{~cm}^{2} ; \mathrm{p}<0.001$ ) (Table 1). There were no correlations between the differences and other variables tested.

The registry was designed to challenge the 2012 ESC/EACTS criteria for surgical treatment of primary severe mitral valve insufficiency. In asymptomatic patients the indications for surgery were rarely stronger than class of recommendation $\mathrm{Ilb}$ - they were mostly symptom-free, with preserved left ventricular function, high likelihood of durable repair, low surgical risk, and left atrial dilatation (volume index $\geq 60 \mathrm{~mL} / \mathrm{m}^{2}$ of body surface area).

The indications for surgery are slightly different in the newly released 2017 ESC/EACTS guidelines for the management of valvular heart disease [2]. What is important, the criteria for classifying the primary MR as severe remain the same. Some new conditions, e.g. an LVESD value of 40 to $44 \mathrm{~mm}$ for the consideration of a surgical intervention in asymptomatic patients with preserved ejection fraction (> 60\%), would reject even more of our patients as potential candidates for surgery because the median LVESD in our study was $35 \mathrm{~mm}$. The guidelines mention that the values are calculated for average-sized adults and may require adaption in patients 
of unusually small or large stature. However, this is not applicable to our analysis because the median body mass index was $26.17 \mathrm{~kg} / \mathrm{m}^{2}$.

Reverse remodelling of cardiac chambers seems to play a huge role in the potential for recovery. Chronic MR is often associated with left atrial enlargement, which is a well-known predictor of adverse cardiovascular events, such as stroke, atrial fibrillation, heart failure, and death [5-7].

Ventricular dimensions alter preoperatively and postoperatively as well. It is important to note that in most cases reported herein they did not exceed normal values before the surgery. However, functional parameters, such as volume and LVEF, may remain compensated, despite changes in myocardial properties [8-10]. Moreover, significant reverse remodelling suggests that the muscle already changed its geometry due to MR. Removing the severe regurgitation jet and allowing the physiological status to resume resulted in a significant change in ventricular dimensions.

Although there are several studies regarding the echocardiographic changes after MVR, such strong statistical evidence in an asymptomatic patient group in short-term observation has not yet been documented.

Initial results from our registry support the concept of early surgical repair, before ventricular remodelling occurs. The study itself has certain limitations: it is a single-centre study with no control group, and the procedures were performed by a single surgeon. Despite this, we believe that the results are a strong argument that may play a huge role in the inevitable discussion.

By now we can conclude that minimally invasive MVR is a safe method of treatment in asymptomatic patients. A spectacular reverse remodelling is visible in six-month follow-up. Further observation will be continued to determine the long-term clinical and echocardiographic outcomes.

Conflict of interest: none declared

\section{References}

1. Vahanian A, Alfieri O, Andreotti F, et al. Guidelines on the management of valvular heart disease (version 2012). Eur Heart J. 2012; 33(19): 2451-2496, doi: 10.1093/eurhearti/ehs109, indexed in Pubmed: 22922415.

2. Baumgartner H, Falk V, Bax JJ, et al. 2017 ESC/EACTS Guidelines for the management of valvular heart disease. Eur Heart J. 2017; 38(36): 2739-2791, doi: 10.1093/eurheartj/ehx391, indexed in Pubmed: 28886619

3. Grigioni F, Tribouilloy C, Avierinos JF, et al. Outcomes in mitral regurgitation due to flail leaflets: a multicenter European study. JACC Cardiovasc Imaging. 2008; 1(2): 133-141, doi: 10.1016/j. jcmg.2007.12.005, indexed in Pubmed: 19356418.

4. Suri RM, Vanoverschelde JL, Grigioni F, et al. Association between early surgical intervention vs watchful waiting and outcomes for mitral regurgitation due to flail mitral valve leaflets. JAMA. 2013; 310(6): 609-616, doi: 10.1001/jama.2013.8643, indexed in Pubmed: 23942679.

5. Benjamin EJ, D'Agostino RB, Belanger AJ, et al. Left atrial size and the risk of stroke and death. The Framingham Heart Study. Circulation. 1995; 92(4): 835-841, indexed in Pubmed: 7641364.

6. Messika-Zeitoun D, Bellamy M, Avierinos JF, et al. Left atrial remodelling in mitral regurgitation--methodologic approach, physiological determinants, and outcome implications: a prospective quantitative Doppler-echocardiographic and electron beam-computed tomographic study. Eur Heart J. 2007; 28(14): 1773-1781, doi: 10.1093/eurheartj/ehm199, indexed in Pubmed: 17562673 .

7. Reed D, Abbott RD, Smucker ML, et al. Prediction of outcome after mitral valve replacement in patients with symptomatic chronic mitral regurgitation. The importance of left atrial size. Circulation. 1991; 84(1): 23-34, indexed in Pubmed: 2060099.

8. Mascle S, Schnell F, Thebault C, et al. Predictive value of global longitudinal strain in a surgical population of organic mitral regurgitation. J Am Soc Echocardiogr. 2012; 25(7): 766-772, doi: 10.1016/j.echo.2012.04.009, indexed in Pubmed: 22609096.

9. Pandis D, Sengupta PP, Castillo JG, et al. Assessment of longitudinal myocardial mechanics in patients with degenerative mitral valve regurgitation predicts postoperative worsening of left ventricular systolic function. J Am Soc Echocardiogr. 2014; 27(6): 627-638, doi: 10.1016/j.echo.2014.02.008, indexed in Pubmed: 24735653.

10. Witkowski TG, Thomas JD, Debonnaire PJ, et al. Global longitudinal strain predicts left ventricular dysfunction after mitral valve repair. Eur Heart J Cardiovasc Imaging. 2013; 14(1): 69-76, doi: 10.1093/ehjci/jes155, indexed in Pubmed: 22848021.

Cite this article as: Gerber W, Sanetra K, Drzewiecka-Gerber A, et al. Echocardiographic evaluation of the results of minimally invasive repair of asymptomatic mitral regurgitation. Kardiol Pol. 2019; 77(1): 56-58, doi: 10.5603/KP.a2018.0227. 